\title{
Educação médica e avaliação: a percepção do professor de um curso de medicina a respeito da aplicação do portfólio como instrumento de avaliação
}

\author{
Medical education and evaluation: the perception of the \\ teacher in a medical course regarding the aplication of \\ the portfolio as an evaluation instrument
}

\author{
Ivete Moura Seabra',2, Nara Macedo Botelho, $1,2,3$, \\ Roseane do Socorro Ferreira dos Santos ${ }^{1,2,4}$, Rafaella Macêdo Monteiro da Cruz ${ }^{2}$, \\ Bárbara da Silva Cavalcante ${ }^{2}$ \\ 'Centro Universitário do Pará, Belém (PA), Brasil. \\ ¿Universidade do Estado do Pará, Belém (PA), Brasil. \\ ${ }^{3}$ Faculdade de Medicina, Universidade do Estado de São Paulo, São Paulo (SP), Brasil. \\ ${ }^{4}$ Internato de Saúde Coletiva, Departamento de Saúde Comunitária, Universidade do Estado do Pará, Belém \\ (PA), Brasil.
}

Recebido: Mar. 26, 2019

Aceito: Ago. 28, 2019

\section{COMO CITAR ESTE ARTIGO}

Seabra IM, Botelho NM, Santos RSF Cruz RMM, Cavalcante BS. Educação médica e avaliação: a percepção do professor de um curso de medicina a respeito da aplicação do portfólio Interdisciplinary Journal of Health Education. 2020Jan-Jun;5(1):1-11. https://doi.org/10.4322/ijhe.2020.001.

\section{CORRESPONDÊNCIA}

Nara Macedo Botelho

Programa de Pós-graduação

profissional Ensino em Saúde na

Amazônia, Centro de Ciências

Biológicas e da Saúde, Universidade do

Estado do Pará.

Travessa Perebebui, 2623, Marco,

CEP 66095-661, Belém, Pará, Brasil.

narambotelho@gmail.com

\section{FONTE DE FINANCIAMENTO}

Nenhuma.

\section{CONFLITO DE INTERESSE}

Os autores declararam não

haver conflitos de interesse.

O estudo foi realizado no

Centro Universitário do Pará

CESUPA, Belém, Pará, Brasil.

Todos os autores leram e aprovam a versão final submetida ao Interdisciplinary Journal of Health Education (IJHE)

\section{RESUMO}

Na saúde, o uso do portfólio é recente, cujo potencial começa a ser explorado, principalmente em instituições de ensino superior como uma forma de inovação da formação médica. Entretanto, ainda há resistências quanto ao uso do instrumento. Objetivo: O objetivo desta pesquisa é identificar a percepção do professor a respeito do portfólio como ferramenta de avaliação formativa, buscando relacionar seu conhecimento do a respeito desse instrumento de avaliação e a eficiência que o mesmo credita na sua utilização. Método: Os dados foram coletados através de entrevistas semiestruturadas realizadas com treze educadores médicos de uma instituição de ensino superior de Belém, que atuam na educação médica há no mínimo três anos e que utilizam o portfólio como instrumento de avaliação formativa dos seus alunos. O protocolo de entrevista foi dividido em: caracterização do sujeito (Idade, sexo, tempo de formação, pós-graduação e tempo na docência) e a entrevista propriamente dita, onde os professores responderam quais variáveis foram identificadas como dificuldades e as percepções quanto à aplicação do portfólio para avaliação. Resultados: Os resultados mostram a importância da avaliação do Portfólio no processo ensino aprendizagem na educação médica, já que todos os sujeitos envolvidos na pesquisa foram unânimes em afirmar que a avaliação é um processo educativo de muita importância e também considerada como um processo para se alcançar resultados. Conclusão: Portanto, conclui-se que, segundo a percepção do professor, a potencialidade do portfólio é a avaliação da evolução do aluno durante todo o processo de ensino aprendizagem, em todas as etapas da aprendizagem permitindo a reflexão tanto do aluno como a do professor, trazendo grandes contribuições para a educação médica.

PALAVRAS-ChaVe: Professor. Portfólio. Metodologia ativa.

\section{ABSTRACT}

In health, the use of potfolio is recent, it's potential starting to be explored on higher education institutions as a innovation on the medical formation. However, there are still resistances to the use of the instrument. Objective: The objective of identifying the professor's perception regarding the portfolio as an instrument of formative evaluation, searching to relate the knowledge of the teachers regarding this evaluation tool and efficiency that they credit to its use. Methods: The data was collected through semi-structured interviews with the thirteen medical educators of a higher education institution in Belém, who acted at medical education for at least three years and used the portfolio as a formative evaluation instrument for their students. The interview's protocol was divided in: subject's characterization (Age, gender, formation time, postgraduate studies and teaching time) and the interview itself, in which the professor answered what variables were identified as difficulties and the perception regarding the application of portfolios for evaluation. Results: The results show the importance of the Portfolio evaluation in the teaching-learning process on medical education, considering that all the subjects involved in the research were unanimous saying that the evaluation is essential and considered necessary to achieve results. Conclusion: 


\section{ijhe}

Therefore, it can be concluded that the potentiality of the Portfolio is the evaluation of the student's evolution during the whole process of learning, allowing reflection to the professor as well as to the student, bringing immense fruits to the Medical Education.

KEYWORDS: Teacher. Portfolio. Active methodology.

\section{Introdução}

A formação médica passou por muitas transformações no último século, desde a sistematização introduzida pelo Relatório de Flexner, no início do século passado ${ }^{1}$. Nas últimas décadas o surgimento de novas tecnológicas no âmbito do diagnóstico e da prevenção colocaram definitivamente em questão os procedimentos tradicionalmente cultivados nos cursos de medicina e produzindo um lento mas, consistente redirecionamento das práticas até então consideradas adequadas. Procedimentos tais como o currículo voltado para as competências e a utilização de cenários de aprendizagem, dentro das Unidades de Saúde, passaram a ser priorizados o que obrigou os cursos de medicina a formularem novas estratégias para preparar os alunos aos novos desafios profissionais a serem superados em sintonia com tais avanços tecnológicos e com o papel social que lhe cabe enquanto agente transformador da sociedade. Nesse contexto, os cursos de medicina têm investido cada vez mais nas metodologias ativas centradas no aluno o que tem, inclusive, feito surgir novas experiências na forma de avaliar o aprendizado dos alunos na graduação do curso de medicina, entre as quais têm se destacado o método de construções de portfólio ${ }^{1-3}$.

Na saúde, o uso do portfólio é recente, cujo potencial começa a ser explorado, principalmente em instituições de ensino superior. O portfólio como uma ferramenta pedagógica de organização planejada de trabalhos ${ }^{4}$ produzidos pelos estudantes, onde apresenta as evidências de sua aprendizagem. É construído a partir da coleção proposital do trabalho do aluno onde fica evidente os seus esforços de realização em uma área específica ao longo do período avaliado ${ }^{5-7}$.

Embora sejam abundantes as referências positivas à utilização do portfólio como um instrumento de avaliação, na educação médica, e por ter um potencial de desenvolver as habilidades críticas e reflexivas nos estudantes, medindo as qualidades difíceis de serem avaliadas pelos métodos convencionais e ao mesmo tempo possibilitar a ligação das experiências práticas com o conhecimento teórico em contextos autênticos ${ }^{5,8}$, tais benefícios nem sempre são alcançados em função da maneira como o portfólio eventualmente está estruturado ou das resistências, tanto por parte de estudantes como de professores, em relação a esse instrumento de avaliação. Tais resistências, algumas vezes, são causadas por percepções equivocadas a respeito das potencialidades do instrumento. Dessa forma, o objetivo desta pesquisa é identificar a percepção do professor a respeito do portfólio como ferramenta de avaliação formativa, buscando relacionar o conhecimento do professor a respeito desse instrumento de avaliação e a eficiência que o mesmo credita na sua utilização.

\section{MÉTODO}

\section{Delineamento da pesquisa}

A pesquisa é um estudo transversal com uma abordagem qualitativa, realizada numa instituição de ensino superior privada, o Centro Universitário do Estado do Pará (CESUPA), que está localizada no Município de Belém, Capital do Estado do Pará. O período da pesquisa foi de Maio de 2014 a Março de 2015.

\section{Processo de Seleção}

O curso de Medicina do CESUPA cumpre as orientações das Diretrizes Curriculares Nacionais, priorizando a promoção da saúde, prevenção de doenças, o tratamento 
e a recuperação da saúde. Tem as metodologias ativas, centradas no aluno, como o PBL (Aprendizado baseado em Problemas) e a problematização, onde o aluno é estimulado a ir em busca do seu conhecimento.

Os professores que participaram da pesquisa tem suas atividades no MISC (Módulo e Interação à Saúde na Comunidade) do curso de Medicina, sendo uma atividade que integra a universidade com a comunidade. Ela inicia no primeiro semestre e finaliza no oitavo semestre do curso. $\mathrm{O}$ aluno tem a possibilidade de, nos oito semestres, ver o trabalho em equipe multiprofissional e interdisciplinar. A metodologia de ensino é a da Problematização. A avaliação é formativa e o Portfólio é o instrumento de avaliação, onde o aluno tem a possibilidade de se auto-avaliar através da reflexão e demonstrar para o professor os conhecimentos adquiridos durante a atividade.

\section{Amostragem}

A pesquisa iniciou com uma casuística de 20 professores médicos que atuavam como docentes no MISC (Módulo de Interação em Saúde na Comunidade). O critério de definição do tamanho da casuística final foi a saturação teórica. Para atingir o objetivo do estudo, foram entrevistados 13 professores médicos que estavam atuando no MISC.

\section{Critérios de inclusão}

Como critérios de inclusão foram usados: professores que pertenciam ao quadro funcional do Centro Universitário e estavam como educadores do Curso de Medicina e que já atuavam na educação médica há pelo menos 03 (três) anos e utilizavam o portfólio como instrumento de avaliação formativa no período da pesquisa.

\section{Instrumentos de coleta}

A coleta de dados foi realizada em Janeiro de 2015, onde primeiramente foi feita uma reunião com os professores médicos do MISC informando sobre a pesquisa que estava sendo proposta.

As entrevistas foram semiestruturadas individuais, gravadas, transcritas e depois analisadas pelos pesquisadores. O protocolo de pesquisa foi dividido em dois tópicos: a caracterização do pesquisado (Idade, sexo, tempo de formação, pós-graduação e tempo na docência) e a entrevista propriamente dita, onde os professores responderam as variáveis que identificaram as dificuldades e as percepções quanto à aplicação do portfólio na avaliação.

Os registros foram feitos através de um gravador, durante toda a entrevista, e posteriormente armazenado em Pendrive e num HD (Hard Disk) externo. Para resguardar a identidade dos pesquisados, foram atribuídos a eles códigos formados pela letra $\mathrm{P}$ seguida de um número crescente. Assim, no momento da análise dos dados, os professores passaram a ser identificados de P1 a P13. Após a coleta de dados às entrevistas foram analisadas individualmente.

Os professores responderam o protocolo de pesquisa que apresentava 10 questões:

- 08 questões para que os professores respondessem de forma reflexiva sobre alguns temas que auxiliariam no entendimento da pesquisa (questão 1 - O que você pensa sobre avaliação?; questão 2 - Quais os instrumentos de avaliação que você utiliza para avaliar seus alunos?; questão 3 - Para você o que é portfólio?; questão 4 - O que você entende como Portfólio Crítico Reflexivo?; questão 7 - Quais as dificuldades que você encontrou para avaliar os Portfólios Críticos Reflexivos de seus alunos?; questão 8 - Quais as potencialidades da aplicação do portfólio?; questão 9 - Quais as fragilidades que você identifica na avaliação dos portfólios desenvolvidos pelos alunos? e a questão 10 - Quais as sugestões que você pode propor para uma melhor organização do conteúdo do portfólio?);

- 01 questão (questão 5) era para que os professores completassem alguns conceitos entre eles: avaliação formativa é...; o portfólio crítico reflexivo é... e auto-avaliação é...; e 
- 01 questão (questão 6) era para que os professores associassem uma palavra a outra através da evocação das palavras, sendo elas: docência, educação continuada, avaliação, reflexão e crítica, sendo que essa questão não trouxe uma contribuição satisfatória para o objeto de estudo, portanto ela não se enquadrou adequadamente em nenhuma categoria temática, ficando, portanto, fora da análise dos resultados.

\section{Análise dos Dados}

A análise dos dados foi então realizada, na seguinte sequência:

Processo de ordenação dos dados - formatação dos conteúdos transcritos e dos dados registrados.

Processo de categorização inicial - a partir de uma releitura exaustiva e repetitiva dos dados, propiciando uma relação interrogativa com eles e permitindo apreender as estruturas de relevância e as ideias centrais.

Processo de análise final - a partir da interpretação das categorias elaboradas e de acordo com o referencial teórico foi se constituindo um texto fundamentado no diálogo entre pesquisadora e os autores.

Os dados obtidos na pesquisa pela análise de conteúdo foram classificados em categorias teóricas, categorias empíricas e unidades de análise. A categoria está relacionada à classificação ou agrupamento de elementos que são sistematizados pelo pesquisador após a pesquisa de campo, ou no decorrer da análise de conceitos em livros, textos e documentos, que neste estudo foram organizadas da seguinte forma:

- CATEGORIAS TEÓRICAS: são entendidas quando se tem leituras convergentes ao tema central do estudo, ou seja, emergem do afunilamento das leituras pertinentes ao objeto de estudo, estabelecem critérios para aprofundar conteúdos, sistematizá-los e assim direcionam a posterior construção dos instrumentais de pesquisa. A análise dos resultados, tomando como parâmetro a fala dos professores $(\mathrm{P})$, permitiu construir cinco categorias temáticas, procurando responder os objetivos específicos do estudo.

\section{Categoria I - Os Conhecimentos sobre avaliação formativa;}

Foram agrupadas as questões: $\mathbf{1}$ (O que você pensa sobre avaliação?) e duas partes da 5 (5.1 Avaliação formativa é... e 5.3 Autoavaliação é...). Essas questões ficaram unidas nessa categoria justamente por elas terem em comum o assunto voltado para a avaliação, nessa categoria foi analisado o conhecimento dos professores sobre a avaliação e autoavaliação.

Categoria II - Os instrumentos de avaliação mais utilizados

Foram agrupadas as respostas da questão 2 (Quais os instrumentos de avaliação que você utiliza para avaliar seus alunos?). Essa questão foi pensada para conhecer quais os instrumentos de avaliação mais utilizados por eles dentro da instituição de ensino que atuavam no momento da entrevista.

Categoria III - Os Conhecimentos sobre o Portfólio

Foram agrupadas as questões: 3 (Para você o que é portfólio?); 4 (O que você entende como Portfólio Crítico Reflexivo?); uma parte da 5 (5.3 Portfólio crítico reflexivo é...) e a 7 (Quais as dificuldades que você encontrou para avaliar os portfólios críticos reflexivos de seus alunos?). Essas questões ficaram unidas nessa categoria justamente por ela terem em comum o assunto voltado para o portfólio desde a sua definição pelos professores como as suas dificuldades de aplicação.

Categoria IV - As Potencialidades do portfólio reflexivo;

Foram agrupadas as respostas da questão 8 (Quais as potencialidades da aplicação do portfólio?). Essa questão foi pensada para conhecer quais as percepções dos professores sobre as potencialidades da avaliação através dos Portfólios dentro da Metodologia da Problematização. 
Categoria V - As fragilidades para avaliação do portfólio reflexivo;

Foram agrupadas as respostas da questão 9 (Quais as fragilidades que você identifica na avaliação dos portfólios desenvolvidos pelos alunos?). Essa questão foi pensada para conhecer quais as percepções dos professores sobre as fragilidades para a avaliação dos Portfólios.

Categoria VI - As Propostas para Organização do Portfólio Reflexivo.

Foram agrupadas as respostas da questão 10 (Quais as sugestões que você pode propor para uma melhor organização do Portfólio?). Finalmente nessa categoria estarão as necessidades de mudanças para a avaliação formativa através dos Portfólios Reflexivos.

- CATEGORIAS EMPÍRICAS: pode surgir da pesquisa de campo ou podem ser pré-estabelecidas; para cada questão formulada ou para cada item do roteiro de entrevista estabelece-se uma categoria, nesta pesquisa, as categorias surgiram depois da pesquisa de campo. Surgiram as seguintes categorias empíricas: Definição de avaliação, Objetivo da avaliação formativa, Objetivos da Auto-avaliação, Aplicabilidade dos Instrumentos de Avaliação, Definição de Portfólio, Aplicabilidade do Portfólio, Finalidade do Portfólio, Dificuldade de aplicação do Portfólio, Potencialidades do Portfólio, Fragilidades do Portfólio, Propostas de mudanças para o Portfólio.

Unidades de análise

É a sistematização das respostas, ou seja, são as informações obtidas através da aplicação dos instrumentais de pesquisa (roteiro da entrevista), emergem dos dados, ou seja, das respostas, similares e convergentes, dos participantes da pesquisa.

É importante entender que as categorias existem para traduzir dados brutos em dados organizados, e esse processo não introduz desvios no material, apenas deixam mais claro os dados, fornecendo uma representação simplificada dos mesmos.

As categorias foram agrupadas em quadros e nos gráficos, colocadas às frequências das unidades de análise, para que se pudessem visualizar melhor os resultados da pesquisa

\section{Aspectos Éticos}

A pesquisa foi aprovada pelo Comitê de Ética em Pesquisa (CEP) do Centro Universitário do Pará (CESUPA), n CAAE 32103714.2.0000.5169, respeitando a resolução de $\mathrm{N}^{\circ}$ 466/12 do Conselho Nacional de Saúde (CNS), com princípios regidos pelo Código de Nuremberg e de Helsinque. Os educadores foram orientados sobre os objetivos do estudo e todos os entrevistados assinaram o TCLE (Termo de Consentimento Livre e Esclarecido).

\section{Resultados e discussão}

\section{Caracterização do sujeito}

A Tabela 1, abaixo, mostra os dados quantitativos referentes ao corpo docente do MISC, $100 \%$ composto por médicos, e tem a finalidade de apresentar as principais informações que caracterizam parte do grupo pesquisado. Do total dos entrevistados (13), 61,5\% são do gênero feminino e 38,5\% do masculino.

Os dados mostram que $16 \%$ dos professores fizeram um curso de especialização, $38 \%$ possui residência médica, $38,5 \%$ fez mestrado e $8 \%$ fez

doutorado. Esses dados diferem dos encontrados no estudo sobre a Dificuldades da Avaliação em um Curso de Farmácia ${ }^{9}$, onde a composição do corpo docente era mista, haviam docentes da área da farmácia, ciências biológicas, química, matemática e pedagogia. 
Tabela 1. Distribuição dos professores médicos do MISC, quanto ao sexo e o curso de Pós-graduação, CESUPA, 2015.

\begin{tabular}{|c|c|c|c|c|c|c|c|c|c|c|}
\hline \multirow{2}{*}{ GÊNERO } & \multirow{2}{*}{$\mathbf{N}^{\circ}$} & \multirow{2}{*}{$\%$} & \multicolumn{2}{|c|}{ ESPECIALIZAÇÃO } & \multicolumn{2}{|c|}{$\begin{array}{l}\text { RESIDÊNCIA } \\
\text { MÉDICA }\end{array}$} & \multicolumn{2}{|c|}{ MESTRADO } & \multicolumn{2}{|c|}{ DOUTORADO } \\
\hline & & & $\mathbf{N}^{\circ}$ & $\%$ & $\mathbf{N}^{\circ}$ & $\%$ & $\mathbf{N}^{\circ}$ & $\%$ & $\mathbf{N}^{\circ}$ & $\%$ \\
\hline FEMININO & 08 & 61,5 & 01 & 8 & 04 & 30 & 02 & 15,4 & 01 & 8 \\
\hline MASCULINO & 05 & 38,5 & 01 & 8 & 01 & 8 & 03 & 23,1 & & \\
\hline TOTAL & 13 & 100 & 02 & 16 & 05 & 38 & 05 & 38,5 & 01 & 8 \\
\hline
\end{tabular}

Fonte: Protocolo de pesquisa.

A mudança no perfil dos professores dos cursos de Medicina conforme indicado na Tabela 1 ganhou relevância a necessidade de formar médicos generalistas, voltados para processos de intervenção mais direta nas comunidades, ao conjugar teoria e prática como parte de um projeto de formação profissional. Ao mesmo tempo em que se coloca em condições de desenvolver diversos papéis entre os quais o de docente. Cada um desses papéis está definido por competências para além das dimensões individuais, interpessoais e sociais do profissionalismo ${ }^{10}$.

Quadro 1. Definição de avaliação formativa citada pelos professores médicos do MISC, CESUPA, 2015.

\begin{tabular}{lc}
\multicolumn{1}{c}{ Definição de avaliação } & Frequência \\
\hline - Processo educativo & 18 \\
\hline - Processo para alcançar resultados & 10 \\
\hline - Processo em construção & 08 \\
\hline - Processo difícil & 08 \\
\hline
\end{tabular}

Fonte: Protocolo de pesquisa.

\section{Definição de avaliação formativa}

Nos resultados descritos no Quadro 1, sobre a definição de avaliação formativa, fica evidente que todos os pesquisados foram unânimes dizer que a avaliação é um processo educativo de muita importância e também considerada como um processo para se alcançar resultados. Esse processo serve até para que o próprio professor faça sua auto-avaliação procurando identificar possíveis erros dentro do processo de construção da avaliação; mas avaliar foi considerado também um processo difícil.

O professor avalia o aluno no seu dia a dia, sendo necessário que seja feito um acompanhamento do seu crescimento e é um processo muito importante realizado ao longo da vida acadêmica. Essa construção é desenvolvida em cada etapa, que o aluno se encontra, e vai acontecer a partir da relação entre professor e aluno. A avaliação formativa dá chances ao professor de conhecer amplamente cada aluno: suas necessidades, seus interesses e suas capacidades ${ }^{11}$. Por isso, muitas vezes, a avaliação é considerada um processo difícil e complicado de ser realizado. Isso ficou bem claro na fala dos professores: P7: "é um momento muito importante de avaliação diária e contínua nas etapas que precisam ser vencidas pelo aluno; ela deve ser feita em várias etapas de acordo com cada uma das habilidades e competências exigidas." Os professores concordam que avaliar é um momento importante e único, pois se pode acompanhar o crescimento individual de cada um e fazer sua própria auto-avaliação como docente.

Mas, para os professores, fica claro que avaliar é um processo difícil e complicado de construir. Na avaliação formativa em alguns momentos, segundo alguns professores, não fica bem estabelecidas as normas para avaliar e a gestão não define o que de fato deva ser avaliado. Apesar de ter um critério pré-estabelecido na maior parte do tempo, mas que ainda assim fica vago a forma de avaliar. 
A avaliação da aprendizagem só funciona se houver clareza do que se deseja, se houver investimento e dedicação na produção dos resultados ${ }^{12}$ é o que um professor citou na sua fala: P10:“É uma forma da gente ver o que é preciso melhorar no nosso trabalho para que possamos alcançar o resultado esperado."

Todo o processo deve ser discutido e por isso se torna um passo muito difícil, porque nem sempre os professores estão disponíveis para fazer os ajustes necessários. Alguns pontos do processo avaliativo que foram levantados devem ser discutidos com os outros professores. É muito importante essa construção dentro do processo educativo, pois só assim o professor pode avaliar o que está ensinando e se o aluno, em formação, está aprendendo dentro da sua realidade. É o que se pode observar nas seguintes falas: P2: "é difícil, porque você precisa ter muita consciência de estar avaliando aquele aluno, pois cada aluno tem uma perspectiva diferente [...]às vezes é muito difícil você dar uma nota para aquele aluno, pois naquela atividade ele não desenvolveu adequadamente, mas em outras ele já se desenvolve bem"

A grande questão de se achar a avaliação difícil e complicada é porque os professores médicos não tem uma formação voltada para a licenciatura, por isso ter a dificuldade de avaliar. Os professores consideraram uma atividade complexa e polêmica, principalmente porque no ambiente universitário, dos cursos da área da saúde, se observou que grande parte do corpo docente não possui formação pedagógica ${ }^{9}$. Toda essa situação torna, portanto, uma demora na compreensão dos processos de avaliação pelos professores.

\section{Objetivos da avaliação formativa}

Nos resultados descritos no Quadro 2, sobre os objetivos de avaliação, fica evidente que os professores foram unânimes em relatar que a avaliação formativa é uma observação diária que ocorre de maneira uniforme nos diversos cenários da formação e que deve seguir os critérios de avaliação definidos pela instituição, para que não ocorram erros durante o processo. Esse processo deve ser bem criterioso para que se possa chegar a um resultado satisfatório. Para que esse processo ocorra, o mais uniforme e preciso, é necessário o compromisso em avaliar, sendo firmado entre os atores participantes dessa construção, no caso o aluno e o professor. O professor tem que manter a sua ética enquanto avaliador para que sua avaliação se condense numa nota final.

Quadro 2. Sobre os objetivos da avaliação formativa citados pelos professores médicos do MISC, CESUPA, 2015.

\begin{tabular}{lc}
\multicolumn{1}{c}{ Objetivos da avaliação } & Frequência \\
\hline - Observação diária & 12 \\
\hline - Critérios para avaliar & 05 \\
\hline - Compromisso em avaliar & 05 \\
\hline - Formação do aluno & 04 \\
\hline - Ver o aluno & 03 \\
\hline - Difícil aplicação & 01 \\
\hline
\end{tabular}

Fonte: Protocolo de pesquisa.

Na relação professor-aluno, tanto aluno como professor tem que ter a consciência de seus papéis, cada qual na sua função dentro do processo ensino aprendizagem. $\mathrm{O}$ aluno tem que aprender construindo seu conhecimento e o professor tem o compromisso de auxiliar na construção adequada desse conhecimento, agindo como moderador nesse desenvolvimento ${ }^{12}$. Através desse compromisso firmado, facilita para o professor, ver o aluno como um todo, mesmo sabendo que algumas vezes esse processo possa se tornar difícil. A seguir alguns trechos das entrevistas que reforçam esses objetivos: 
P1: " eu vejo todos os parâmetros: a frequência, o interesse, a assiduidade..."

P2: " é avaliar o aluno conforme o critério que ele vai ser avaliado e o critério que está sendo desenvolvido nele."

P10: " é uma metodologia que você consegue avaliar o aluno como um todo; a participação dele em todas as aulas e em todos os trabalhos propostos naquele dia. É uma forma de gente ver o que é preciso melhorar no nosso trabalho para que possamos alcançar o resultado esperado."

A avaliação formativa é toda planejada, seguindo os critérios padronizados para o curso de Medicina dentro das Metodologias Ativas. O professor, no dia da atividade, está à disposição do aluno para auxiliá-lo no que for preciso, pois nesse dia o aluno tem que agir e refletir no que está fazendo, é a chamada reflexão na ação. Dentro do cenário prático, das Unidades Básicas de Saúde, é trabalhado a problematização, portanto as ações do dia são imprevisíveis e as reações dos alunos são espontâneas, vai do professor mediar à atividade do dia, para que no final o aluno relate qual a experiência vivenciada. É preciso ter cautela para se avaliar, pois a avaliação pode servir para propósitos positivos ou negativos, dependendo da interação do professor com os alunos ${ }^{11}$.

Quando o professor tem um contato maior com seus alunos, permite que ele tenha um conhecimento amplo deles e até mesmo de problemas que eles possam estar vivenciando, podendo encorajá-los para atravessar esses obstáculos de uma forma tranquila sem prejudicar seu aprendizado. Esse professor que fica em várias etapas com os alunos pode fazer sua avaliação formativa sem medo de errar, já que vem avaliando, individualmente cada aluno, de outras etapas e acompanha de perto seu progresso e crescimento, diante da profissão que o espera. Nesse caso a avaliação formativa é acompanhada de muita responsabilidade pelo professor, pois boa parte da personalidade do profissional em formação vai depender desse professor. As críticas feitas, pelo professor, devem ser adequadas e construtivas, fazendo com que o aluno reflita nas suas fragilidades e as torne uma fortaleza.

Ficou claro no estudo que a avaliação formativa se observa, no dia a dia, a evolução do aluno, através de critérios previamente estabelecidos, de como ele está se inserindo nas atividades, como está seu relacionamento interpessoal com os demais profissionais e demais colegas, sua compostura e sua atitude. O professor tem a oportunidade de acompanhar e conhecer o que o aluno aprendeu e o que ainda não aprendeu ${ }^{11}$.

No cenário prático, quando o professor está circulando de consultório em consultório observando o desempenho do aluno na sua ação, ele está analisando-o em cada etapa. É um momento primordial da avaliação formativa, portanto ela deve ser praticada com ética e responsabilidade. Em contextos educativos, avaliação é chamada a desempenhar funções essencialmente formativas. Isso quer dizer que a avaliação deve estar a serviço de quem aprende e, ao fazê-lo, simultaneamente estará a serviço de quem ensina ${ }^{13}$.

O professor tem que entender que o meio, em que o aluno vive, pode contribuir com oportunidades para a sua aprendizagem. Numa perspectiva construtivista da avaliação a questão da qualidade do ensino deve ser analisada, em termos dos objetivos efetivamente perseguidos, no sentido do desenvolvimento máximo possível dos alunos, à aprendizagem ${ }^{14}$.

Os professores consideraram a avaliação um processo difícil de ser aplicado, no entanto eles têm que assumir quando a aprendizagem não foi adequada. É necessário que os professores possam discutir os caminhos para melhorar a avaliação. É muito importante discutir os entendimentos sobre os fracassos de aprendizagem, porque "as enunciadas culpas" sobre tais fracassos podem significar um dos maiores entraves à discussão entre professores sobre a sua prática avaliativa nas universidades ${ }^{14}$.

\section{As potencialidades do portfólio reflexivo}

Nos resultados descritos no Quadro 3, sobre as potencialidades do portfólio, surgiu em maior frequência foi a avaliação da evolução do aluno dentro do processo de construção do saber. Nessa construção do saber o portfólio reforça o aprendizado 
Quadro 3. Sobre as potencialidades do Portfólio citadas pelos professores médicos do MISC, CESUPA, 2015.

\begin{tabular}{ll}
\multicolumn{1}{c}{$\begin{array}{c}\text { Subcategoria: Potencialidades da } \\
\text { aplicação do portfólio }\end{array}$} & Frequência \\
\hline - Avalia a evolução do aluno & 09 \\
\hline - Importante instrumento de avaliação & 08 \\
\hline - Autoavaliação do professor & 08 \\
\hline - Permite a reflexão & 06 \\
\hline - Permite o Feedback & 06 \\
\hline
\end{tabular}

Fonte: Protocolo de pesquisa.

contínuo também do professor. Possibilita ao professor fazer a sua auto-avaliação, permitindo que com isso possa fazer mudanças em sua prática diária, podendo fazer melhorias de como agir como docente.

Aolongo do semestre o professor pode avaliar a evolução do aluno, relacionado com sua participação nas atividades, o seu interesse e atitude. Através do portfólio professor passa a ter conhecimento de possíveis falhas cometidas pelos alunos, assim com, as suas próprias

. Para que o trabalho se mantenha sempre coerente os professores têm que cobrar sempre a reflexão do aluno, sua percepção da atividade, para que o portfólio não passe a ser meramente um instrumento mecânico nas atividades, fazendo com que o aluno perca o interesse em relatar suas percepções do dia a dia. Avaliação através de portfólios requer tempo, paciência e conhecimento do instrumento.

Portanto, em relação a maior potencialidade do portfólio, na percepção dos professores, é avaliar a evolução do aluno e observar seu amadurecimento ao longo das etapas. Sendo assim, isto possibilita ao professor um comprometimento ao se fazer a avaliação, melhorando sua experiência em fazer uma avaliação mais reflexiva dos portfólios dos alunos. O objetivo deste processo é aprender com a experiência ${ }^{15}$. A reflexão torna-se, assim, uma condição para o desenvolvimento profissional. Através da reflexão, as mudanças podem ser propostas para que se alcance um ideal e na prática diária o próprio professor possa fazer melhorias na sua prática educacional. Quando o professor médico reconhece suas dificuldades permite que faça uma avaliação mais reflexiva dos portfólios dos alunos. É o que se observa no relato dos professores P10: "em que a gente pode melhorar como docente porque tem aluno que coloca mesmo o que poderia ter sido feito diferente ou onde poderíamos melhorar e isso enriquece a gente cada vez mais na nossa atividade diária com o aluno." E o P11: "o professor, a partir da leitura do portfólio, pode melhorar a técnica de abordagem dele e o seu desenvolvimento, como apresentar determinado conteúdo e o que se precisa."

Os professores tomam decisões constantemente ${ }^{16}$, mas de forma geral fazem isso de maneira inconsciente ou rotineira, sem se aprofundar nas razões por que as tomam e nem pensam se é possível agir de outra maneira. A avaliação é a atividade que mais impulsiona a mudança, já que, possibilita a conscientização de alguns fatos e a análise de suas possíveis causas e soluções. Algumas propostas foram levantadas pelos professores, entre elas a discussão em grupo a cada semestre, da melhor maneira de avaliar o aluno e o portfólio, procurando a melhoria do grupo de docentes, indo em busca do crescimento docente no processo ensino aprendizagem.

Observar-se também que os professores médicos reconhecem que o portfólio é um importante instrumento de avaliação diária, contribuindo com isso para acompanhar a evolução dos alunos ao longo das etapas, mas que as discussões sobre os pontos positivos e negativos do portfólio deveriam ser pautas constantes a cada semestre, para que possíveis erros possam ser corrigidos pelos professores. Eles relatam que não conhecem de fato a utilização correta do portfólio, para isso o grupo de docente do MISC, precisa se apropriar mais desse instrumento, para que no futuro possa utilizar o instrumento com mais clareza, sendo necessário o fortalecimento das oficinas de avaliação e os instrumentos de avaliação, entre eles o portfólio. 
Na percepção dos professores as normas para o portfólio devem existir, para que o aluno tenha um direcionamento sobre o que vai refletir. O portfólio é um importante instrumento de avaliação formativa ${ }^{16}$ e de aprendizagem. Portanto, não apenas serve para identificar o que se sabe, como também, sobretudo, para refletir sobre o conhecimento que se tem e tomar as decisões de mudanças, caso seja necessário.

O portfólio serve como um instrumento de auto-avaliação para o momento atual, como para o futuro. O professor precisa reconhecer que o portfólio tem inúmeras potencialidades, até para sua própria auto-avaliação, pois no texto escrito pelo aluno, poderá haver as condutas prescritas pelo professor e a partir das anotações este pode refletir no que precisa melhorar.

A avaliação existe para que se conheça o que o aluno já aprendeu, e se providencie os meios para que ele aprenda o necessário e para a continuidade dos estudos, ou seja, avalia-se para promover a aprendizagem, de uma perspectiva formativa ${ }^{17}$.

Os professores reconhecem que o portfólio é um instrumento para reflexão, pois permite que o aluno expresse sua vivência diária e reflita no que fez de positivo ou onde falhou, com isso podendo corrigir suas falhas melhorando o curso de sua aprendizagem. Um dos pontos positivos do portfólio, é avaliar a reflexividade do aluno.

Na avaliação formativa, através da construção do portfólio, há a participação ativa do aluno, bem como a criação de uma cultura de avaliação desvinculada de nota, promoção ou reprovação, articulada a ideia de que todos podem aprender ${ }^{17}$, mas para que essa construção transcorra livre é preciso que o professor estimule o aluno numa reflexão contínua do seu aprendizado.

No portfólio o aluno pode transcrever, com o estimulo do professor, a experiência vivida no dia da sua atividade. Pelo portfólio ter sido considerado um instrumento de reflexão e uma possibilidade de relatar a sua experiência, fazendo com isso um acompanhamento do aluno em cada etapa; o portfólio é "como um instrumento que permite acompanhar o desenvolvimento do aluno". ${ }^{18}$

Uma potencialidade em evidência é a possibilidade de fazer o feedback, pois com o retorno para o aluno, o professor tem a possibilidade de observar os pontos positivos ou onde esse aluno precisa melhorar, permitindo com isso uma melhor comunicação entre professor e aluno. Permitindo que o próprio professor tome decisões acertadas, para as mudanças necessárias, no processo ensino aprendizagem, mas que para isso o professor tem que ter domínio do instrumento que está utilizando para avaliar.

Através do feedback, permite que o professor, faça uma análise de cada aluno. O portfólio é um instrumento que permite analisar, avaliar, executar e apresentar as narrativas das produções resultantes das atividades desenvolvidas num determinado período pelo aluno ${ }^{18}$.

Anarrativa provoca mudanças na forma como as pessoas compreendem a si próprias e aos outros. É um processo profundamente emancipatório em que o sujeito aprende a produzir sua própria formação, autodeterminando a sua trajetória ${ }^{19}$. Portanto a grande importância do feedback é essa, o professor junto ao aluno construindo uma trajetória de conhecimentos.

Um ponto positivo para o portfólio é que ele permite que o aluno faça uma reflexão oral, recebendo de imediato o feedback pelo professor, e a reflexão escrita e isso permite que o aluno desenvolva as habilidades reflexivas e da escrita ${ }^{20}$, fazendo com que o aluno identifique suas fragilidades e fortalezas, podendo nesse momento o professor intervir pontuando os pontos positivos e negativos de cada estudante.

\section{Conclusão}

Pode-se observar que os professores conhecem a avaliação formativa como ela se apresenta para eles através de um processo educativo que deve ser observado diariamente utilizando-se de critérios. É um conhecimento empírico, que foi 
fortalecido pelo entendimento da maioria dos professores, sendo que, esse processo precisa ter todos os critérios avaliativos normatizados pela instituição para que não se cometa erros ou injustiças no momento da avaliação; para isso é necessário o fortalecimento das oficinas de avaliação.

Ficou evidente que a potencialidade do portfólio é a avaliação da evolução do aluno durante todo o processo de ensino aprendizagem, em todas as etapas da aprendizagem, permitindo a reflexão tanto do aluno como a do professor. Sendo essa potencialidade a primordial entre tantas outras, portanto é a maior contribuição que o portfólio pode trazer para a educação médica.

\section{Referências}

1. Norcini JJ, Banda S. Increasing the quality and capacity of education: The challenge for the 21 st century. Med Educ. 2011;45(1):81-6. http://dx.doi.org/10.1111/j.1365-2923.2010.03738.x. PMid:21155871.

2. Mausdsley G, Strivens J. 'Science', 'critical thinking' and 'competence' for Tomorrow's Doctors. A review of terms and concepts. Med Ed. 2000;34:53-60.

3. Gordon D, Karle H. The state of medical and health care education: a review and commentary on the lancet commission report. World Med Health Policy. 2012;4(1):1-18. http://dx.doi.org/10.1515/1948-4682.1219.

4. Ambrósio M. O uso do Portfólio no ensino superior. Petrópolis (RJ): Vozes; 2013.

5. O'Sullivan P, Greene C. Portfolios: Possibilities for addressing emergency medicine resident competencies. Acad Emerg Med. 2002;9(11):1305-9. http://dx.doi.org/10.1197/aemj.9.11.1305. PMid:12414486.

6. Driessen E, van der Vleuten C, Schuwirth L, van Tartwijk J, Vermunt J. The use of qualitative research criteria for portfolio assessment as an alternative to reliability evaluation: A case study. Med Ed. 2005;39(2):214-20. http://dx.doi. org/10.1111/j.1365-2929.2004.02059.x.

7. Salzman D, Franzen D, Leone K, Kessler C. Assessing practice-based learning and improvement. Acad Emerg Med. 2012;19(12):1403-10. http://dx.doi.org/10.1111/acem.12026. PMid:23279247.

8. Nairn S, O'Brien E, Traynor V, Williams G, Chapple M, Johnson S. Student nurses' knowledge, skills and attitudes towards the use of portfolios in a school of nursing. J Clin Nurs. 2006;15(12):1509-20. http://dx.doi.org/10.1111/j.13652702.2005.01432.x. PMid:17118073.

9. Gomes AJPS, Ortega LN, Oliveira DG. Dificuldades da avaliação em um curso de farmácia. Rev Aval Ed Sup (Online). 2010;15(3):203-21. http://dx.doi.org/10.1590/S1414-40772010000300011.

10. Bennett D, McCarthy M, O’Flynn S, Kelly M. In the eye of the beholder: student perspectives on professional roles in practice. Med Ed. 2013;47(4):397-407.

11. Villas Boas BMF. Portfólio, avaliação e trabalho pedagógico. 8. ed. Campinas, (SP): Papirus; 2012.

12. Luckesi CC. Avaliação da aprendizagem: componente do ato pedagógico. 1. ed. São Paulo: Cortez; 2011.

13. Sacristán JG, Gómez AIP, Rodríguez JBM, Santomé JT, Rasco FA, Méndez JMA. Educar por competências: o que há de novo? Porto Alegre: Artmed. 2011.

14. Hoffman JML. Avaliação Mediadora: uma prática em construção da pré-escola à universidade. Porto Alegre: Editora Mediação. 2009.

15. Driessen E, van Tartwijk J, Overeem K, Vermunt J, van der Vleuten C. Conditions for successful reflective use of portfolios in undergraduate medical education. Med Ed. 2005; 39(12):1230-5. http://dx.doi.org/10.1111/j.1365-2929.2005.02337.x.

16. Sanmartí N. Avaliar para aprender. Porto Alegre: Artmed; 2009.

17. Araújo AO, Moraes Júnior VF. Avaliação de aprendizagem: Uma experiência do uso do portfólio em um curso de ciências contábeis. Ver Amb Cont. 2012;4(1):36-50.

18. Alvarenga G. Portfólio: O que é e para que serve? Rev Olh Mág. 2001;8(1):18-21.

19. Cunha MI. Conta-me Agora! As narrativas como alternativas pedagógicas na pesquisa e no ensino. Rev Facul Ed. 1997; 23(1-2). http://dx.doi.org/10.1590/S0102-25551997000100010.

20. Brennan K, Lennie S. Students' experiences and perceptions of the use of portfolios in UK preregistration dietetic placements: A questionnaire-based study. J Hum Nutr Diet. 2010;23(2):133-43. http://dx.doi.org/10.1111/j.1365-277X.2009.01028.x. PMid:20113384.

\section{Contribuição dos autores}

Ivete Moura Seabra participou de todas as etapas da pesquisa e da confecção do manuscrito. Roseane do Socorro Ferreira dos Santos contribuiu com a coleta de dados através das entrevistas, análise dos dados e confecção do manuscrito. Nara Macedo Botelho participou na concepção inicial, acompanhamento, orientação do estudo e elaboração do manuscrito. Rafaella Macêdo Monteiro da Cruz e Bárbara da Silva Cavalcante contribuíram na análise de dados, confecção do manuscrito e demais correções 